
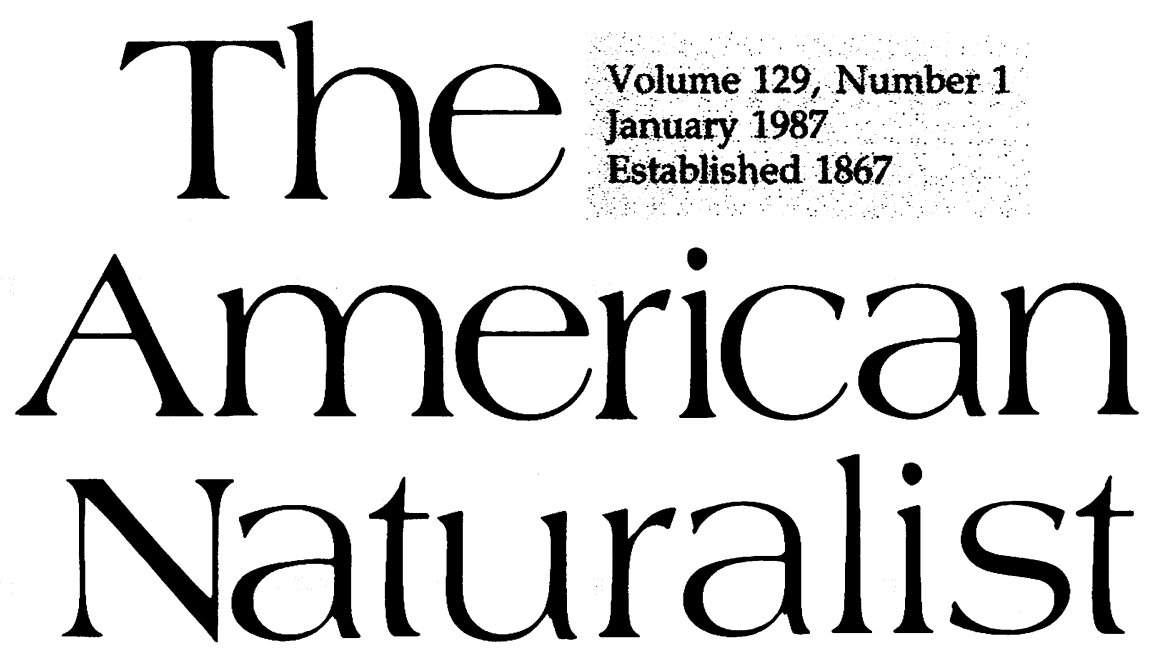

Published for the American Society of Naturalists by The University of ChicagoPress 


\title{
ENVIRONMENTAL TOLERANCE
}

\author{
Michael LyNCH* and Wilfried Gabriel \\ Max Planck Institute for Limnology, Department of Physiological Ecology, Postfach 165, \\ D-2320 Plön, Federal Republic of Germany
}

Submitted August 8, 1985; Revised May 12, 1986; Accepted August 18, 1986

\begin{abstract}
The success of a species, its numbers, sometimes its size, etc., are determined largely by the degree of deviation of a single factor (or factors) from the range of optimum of the species. Victor E. Shelford (1913, p. 303)
\end{abstract}

These words, written by one of the founders of ecology at an early stage in his career, are so deeply embedded in ecological thought that they sound quite trite. Although Shelford's "law of tolerance" is still given significant coverage in some ecology texts (Odum 1971), it has largely been supplanted by the concept of the niche (Whittaker and Levin 1975), which underlies many ecological and evolutionary problems of current interest. Among investigators in evolutionary ecology and ecological genetics, there is much interest in the way in which natural selection interacts with the genome to determine a population's fitness response to different gradients of density-independent and density-dependent factors. In many areas of applied ecology, such as toxicity testing and the development of new crop varieties, a substantial proportion of research focuses on the sensitivity of different genotypes, populations, and/or species to environmental extremes.

In the following, we refer to the response of a genotype's total fitness over an environmental gradient as a tolerance curve. Our definition is a special case of the norm of reaction of Woltereck (1909) and Schmalhausen (1949), which relates the phenotypic expression of a genotype to its environment. Although a genotypefocused definition necessarily introduces some analytic and empirical difficulties, it is an essential starting point in any effort to understand the mechanisms underlying a population-level response to an environmental gradient. The significance of this point was considered first by Van Valen (1965) and later by Roughgarden (1972), who drew a distinction between the within- and betweenphenotype components of niche width. The sensitivity of a population to environmental extremes is a function of both the between-individual variance in environmental optima and the within-individual breadth of adaptation.

The focus of this paper is threefold. First, we wish to point out some of the

${ }^{*}$ Present address: Department of Ecology, Ethology, and Evolution, University of Illinois, Shelford Vivarium, 606 East Healey Street, Champaign, Illinois 61820. 
proximate causes that interact to shape a genotype's tolerance curve and some of the difficulties in identifying them. Second, we consider how temporal and spatial variation in the environment may influence the evolution of specific properties of the tolerance curve. Finally, we discuss a statistical protocol for the estimation of tolerance-curve parameters. We emphasize at the outset that in order to present some of the fundamental concepts of this paper without being overly technical, we have relied on a number of mathematical assumptions, particularly with respect to the form of certain distribution functions. Even with the simplifications, our results indicate that, from both an ecological and an evolutionary perspective, the complex issue of environmental tolerance is unlikely to be resolved with models that ignore explicit details about the genotype-phenotype-environment interface. Thus, although the concepts that we present are intended to be general, the extent to which our exact mathematical expressions can be carried over to natural populations will be resolved only after considerable empirical work.

In its simplest form, the tolerance curve of a genotype is defined by an environmental optimum and a measure of equitability of fitness over the environmental gradient (hereafter, the breadth of adaptation). Thus, we consider a form of bivariate evolution. At the least, a theory for tolerance-curve evolution requires the explicit incorporation of temporal and/or spatial variation in environmental parameters. Environmental heterogeneity, resulting from external circumstances or from modifying forces generated by the population itself, is ubiquitous and must play a leading role in shaping the breadth of adaptation of a population. In the absence of such variation, genetic variance at the population level and ecological generalism at the individual level is difficult to explain without invoking a balance between selection and mutation (or between selection and migration) (Lande 1976), frequency- or density-dependent selection (Slatkin 1979), or overdominance (Gillespie 1984).

As with all characters, the evolution of environmental tolerance may also depend greatly on certain aspects of population structure such as the mating system and dispersal strategy. Because of the considerable complexities of these issues, however, we have chosen to restrict our initial attention to the issues mentioned in the preceding paragraph. The focus of this study is an asexual population exposed to a single environmental gradient that is independent of population density and phenotypic composition. The confinement of our analysis to asexual populations does not seem overly restrictive when one considers the vast number of unicellular and multicellular organisms that periodically or entirely rely on asexual replication (Bell 1982).

There are additional reasons for choosing an asexual model. First, we wish initially to construct an evolutionary model that has a realistic genetic basis without being overly cumbersome. Environmental optima and breadths of adaptation are based on dozens, perhaps hundreds, of gene loci, and the complexities of linkage and gene interactions that might be involved could make a multiple-locus model extremely tedious. Since the genome of an asexual organism is functionally a single "supergene," such complexities do not enter an asexual model. Second, we demonstrate that a complete analysis of the parameters of the tolerance curve (i.e., the practical application of the theory) is possible only with organisms that can be propagated asexually. 
At least three types of existing studies are related to the issue of tolerance-curve evolution. The most notable investigations have focused explicitly on the development of an evolutionary theory for niche width (Levins 1968; Roughgarden 1972; Bulmer 1974; Slatkin and Lande 1976; Felsenstein 1979; Christiansen and Loeschcke 1980; Slatkin 1980; Taper and Case 1985). In addition, one might consider the large number of theoretical studies on the maintenance of polymorphism at single loci in spatially and temporally variable environments (Levene 1953; Haldane and Jayakar 1963; Gillespie and Langley 1974; Karlin and Lieberman 1974; Gillespie 1976, 1978; Templeton and Rothman 1978, 1981; Matsuda and Gojobori 1979; Maynard Smith and Hoekstra 1980; Takahata 1981; and references therein). Finally, the literature on plant and animal breeding is replete with empirical and methodological studies on genotype-environment covariance (Bulmer 1980; Falconer 1981; Via and Lande 1985).

The niche-width models are most closely related to a theory for the evolution of environmental tolerance. Although theoretical studies on the evolution of niche width have probably provided a great deal more insight into this complex problem than would ever have emerged with purely verbal arguments, their primary emphasis has been on the distribution of specified phenotypes under different selective regimens. None of them has explicitly considered the proximate or ultimate causes of the tolerance curve itself, although most could be extended to such an analysis. Many of these studies (most notably Roughgarden 1972; Slatkin 1980; Taper and Case 1985) have focused on the extremely complicated case of density-dependent gradients and, of necessity, rely on numerous assumptions about rates of increase, carrying capacities, and competition coefficients for resources and consumers.

Two additional limitations of current niche theory may be pointed out. First, with the exception of Slatkin and Lande (1976), the theory of the evolution of niche width has considered only deterministic environments. Although spatial variation can legitimately be ignored under some population structures (Slatkin and Lande 1976; Felsenstein 1979), in general, this is not true for temporal heterogeneity (Slatkin and Lande 1976). Second, except in the study of Taper and Case (1985), the within-individual component of niche width has been assumed completely invariant. Under this restriction, variation in breadth of adaptation is purely a population phenomenon resulting from individual variation in environmental optima. Even though such an assumption is often required for mathematical tractability, and although it may be true that the intensity of selection on the environmental optimum may be greater than that on the breadth of adaptation, there seems to be little biological justification for assuming that a character as complex as breadth of adaptation will be immune to environmental and genetic effects.

The theory outlined below eliminates some of these problems. It also indicates, however, that Shelford may not have greatly overstated the case when he wrote, "The results of these five years of labor will not be pleasing to many zoologists because the principles of evolution, heredity, etc., have not been correlated. Their omission, however, has not been due to any prejudice against their introduction, but rather to the fact that they can only occasionally be related to this line of organization."' (1913, p. vi.) 


\section{DETERMINANTS OF A GENOTYPE'S TOLERANCE CURVE}

We represent the tolerance curve for individuals of phenotype $\mathbf{z}$ over a single environmental gradient as $w(\mathbf{z} \mid \phi)$, where $w$ represents fitness and $\phi$ is a continuously distributed environmental variable. Since we treat $\phi$ as independent of the density and frequency of phenotypes, the following theory is most relevant for physical gradients and some chemical ones (e.g., temperature, light intensity, moisture content, $\mathrm{pH}$ ). It may also apply to essential nutrients that become toxic at high concentrations. Specifically, we rely on the bivariate phenotypic function

$$
w\left(z_{1}, z_{2} \mid \phi\right)=\left(2 \pi z_{2}\right)^{-1 / 2} \exp \left[-\left(z_{1}-\phi\right)^{2} / 2 z_{2}\right] .
$$

For this model, $w\left(z_{1}, z_{2} \mid \phi\right)$ is a Gaussian function with environmental optimum $z_{1}$ and "variance" $z_{2}$. We adopt $\left(z_{2}\right)^{1 / 2}$ as a measure of a phenotype's breadth of adaptation, that is, of the sensitivity of a phenotype's fitness to environmental change. Note that as $\left(z_{2}\right)^{1 / 2}$ increases, the function $w\left(z_{1}, z_{2} \mid \phi\right)$ becomes flatter; that is, fitness is less influenced by a change in the environmental state, $\phi$.

Our reliance on the Gaussian function derives from the common observation for density-independent gradients (usually at the population level) that extreme conditions are lethal or nearly so and that fitness is maximized at a single intermediate point on the gradient (Odum 1971; Ricklefs 1973). If these conditions are met, an individual tolerance curve that is not normal on the direct scale of measurement can almost always be rendered approximately normal by an appropriate scale transformation (Wright 1968). However, radical differences in the mathematical form of the tolerance curve between members of the same population would greatly compromise the generality of the following theory. In the case of radical differences among population members, a transformation to normality that was successful for one individual would be counterproductive for others. Note also that the Gaussian function has the property

$$
\int_{-\infty}^{+\infty} w\left(z_{1}, z_{2} \mid \phi\right) d \phi=1 ;
$$

thus, any increase in the breadth of adaptation will be accompanied by a decline in fitness in the optimal environment. We therefore assume a "jack-of-all-trades is a master of none" conflict.

Before proceeding, let us compare equation (1) with the Gaussian fitness function that is frequently used in models of stabilizing selection of polygenic traits (Robertson 1956; Latter 1970; O’Donald 1970; Slatkin 1970, 1979; Lande 1976; Feldman and Cavalli-Sforza 1979; Kirkpatrick 1982; Lynch and Gabriel 1983; and references above). In these models $\phi, z_{1}$, and $\left(z_{2}\right)^{1 / 2}$ are measured on the phenotypic rather than the environmental scale. The optimal phenotype is then $\phi$, and $\left(z_{2}\right)^{1 / 2}$ is inversely related to the intensity of stabilizing selection. Both $\phi$ and $\left(z_{2}\right)^{1 / 2}$ are assumed to be fixed by the environmental setting and equal for all individuals (for one exception to this treatment of $\left(z_{2}\right)^{1 / 2}$, see Taper and Case 1985). Under these circumstances, only the distribution of $z_{1}$ evolves.

Thus, our use of equation (1) to define the tolerance curve reflects a fundamental departure from the traditional interpretation of Gaussian fitness functions in 
two ways: first, all parameters of our model are on environmental rather than phenotypic scales; and second, individuals vary in both $z_{1}$ and $z_{2}$. The usual treatment of $z_{2}$ as a constant appears to be so well accepted that it is almost never explicitly stated as an assumption in stabilizing-selection models. In our model, however, absolute constancy of $z_{2}$ would imply that genetic variance for tolerance does not exist. This is certainly not true (Parsons 1983), and such an interpretation would obviously impose serious constraints on the analysis of problems related to the evolution of the breadth of adaptation. The phenotypes $z_{1}$ and $z_{2}$ are generally functions of many biochemical, physiological, and morphological attributes. Unless all the genes underlying these attributes are fixed, which seems unlikely, $z_{1}$ and $z_{2}$ are heritable traits subject to natural selection.

For the simple case in which the optimal environmental state of an individual is perfectly correlated with the phenotypic value of a single character, our use of an environmental instead of a phenotypic measure would be equivalent to a scale transformation. In most cases, however, the optimal environmental state depends on many characters, and any attempt to relate total fitness to a single trait might result in considerable inaccuracy (Lande and Arnold 1983). Direct use of the environmental gradient avoids this problem, since $w\left(z_{1}, z_{2} \mid \phi\right)$ is a composite measure of fitness that integrates all properties of the phenotype. The cost of this approach is that it obviates the possibility of predicting the evolutionary dynamics of the individual characters defining fitness. This is a general problem of all models of phenotypic evolution. For example, a selection theory for height is not necessarily a theory for the length of individual parts.

Although we consider only a gradient of a single, independent environmental variable, we are not denying the importance of covariance between environmental variables. Just as the response of single characters to selection may be severely constrained by correlations between other selected characters resulting from pleiotropy, the evolution of a tolerance curve along one environmental gradient depends on the joint distribution of different environmental properties (such as temperature and humidity) to which individuals are exposed. For now, however, many of our general points can be made without recourse to multivariate modeling and matrix notation. In order to account for multiple environmental factors in future work, a multivariate form of equation (1) would need to be adopted, in which case $z_{1}$ and $\phi$ would become vectors and $z_{2}$ would become a "covariance" matrix.

\section{Developmental Noise}

For a single environmental gradient, clonal fitness is a function of two genotypic properties: $g_{1}$, the optimal environmental state, and $g_{2}$, the genetic contribution to the variance of the tolerance curve. However, through random noise in developmental pathways, maternal effects, and/or physiological acclimation, an individual's optimal environmental state and/or its breadth of adaptation may differ from the expectations $g_{1}$ and $g_{2}$. Thus, the phenotype $\left(z_{1}, z_{2}\right)$ of individual $x$ of the clone may be written as $z_{1}(x)=g_{1}+e_{1}(x)$ and $z_{2}(x)=g_{2}+e_{2}(x)$, where the $e(x)$ represent deviations. By definition, the expected values of $e_{1}(x)$ and $e_{2}(x)$ are equal to zero. Quantitative geneticists generally refer to $e_{1}$ and $e_{2}$ as environmental 
deviations. In order to avoid semantic difficulties, however, we refer to them as developmental noise. We rely on the usual assumption that the distribution of $e_{1}$ is independent of $g_{1}$. Since $z_{2}>0$ by definition, however, the lower limit of $e_{2}$ is $-g_{2}$, and $e_{2}$ and $g_{2}$ cannot be strictly independent.

The tolerance curve for genotype $\left(g_{1}, g_{2}\right)$ is

$$
w\left(g_{1}, g_{2} \mid \phi\right)=\int_{0}^{+\infty} \int_{-\infty}^{+\infty} w\left(z_{1}, z_{2} \mid \phi\right) p\left(z_{1}, z_{2} \mid g_{1}, g_{2}\right) d z_{1} d z_{2},
$$

where the double integration is over the domain of possible $\left(z_{1}, z_{2}\right)$, and $p$ denotes frequency. We assume that the conditional probability distributions for $z_{1}$ and $z_{2}$ are independent, such that

$$
p\left(z_{1}, z_{2} \mid g_{1}, g_{2}\right)=p\left(z_{1} \mid g_{1}\right) p\left(z_{2} \mid g_{2}\right) .
$$

The developmental variances for the two conditional distributions are $V_{E 1}$ and $V_{E 2}$, respectively. We further assume that the joint action of many environmental effects on the environmental optimum results in a normal conditional distribution:

$$
p\left(z_{1} \mid g_{1}\right)=\left(2 \pi V_{E 1}\right)^{-1 / 2} \exp \left[-\left(z_{1}-g_{1}\right)^{2} / 2 V_{E 1}\right] .
$$

Although $p\left(z_{2} \mid g_{2}\right)$ is also likely to be influenced by a number of different environmental factors, it cannot be strictly normal because a variance cannot be less than zero. We assume that no individuals are so narrowly adapted that $z_{2}=0$, which implies $p\left(0 \mid g_{2}\right)=0$, and that $p\left(z_{2} \mid g_{2}\right)$ has a single peak. A number of distribution functions satisfy these conditions (Lynch and Gabriel 1986). Those that we have focused upon share several qualitative properties: the mode is less than the mean of $z_{2}$; as $V_{E 2}$ approaches zero, $p\left(z_{2} \mid g_{2}\right)$ approaches a normal distribution with mean of approximately $g_{2}$ and variance of approximately $V_{E 2}$; and as $V_{E 2}$ approaches infinity, $p\left(z_{2} \mid g_{2}\right)$ becomes increasingly L-shaped. We rely on a function that most easily yields an analytic solution, a beta distribution of the second kind (Kendall and Stuart 1977, p. 163). In the Appendix we derive a special form of this function (eqs. A2, A3) that satisfies the conditions of expectation $\mathrm{E}\left(z_{2}\right)=g_{2}$ and variance $\operatorname{var}\left(z_{2}\right)=V_{E 2}$.

The genotypic tolerance curve is obtained by substituting equations (1), (4), (5), (A2), and (A3) into equation (3) and integrating. The complete solution is given in the Appendix, where we also show that the genotypic tolerance curve is closely approximated by

$$
w\left(g_{1}, g_{2} \mid \phi\right)=(2 \pi V)^{-1 / 2} \exp \left[-\left(g_{1}-\phi\right)^{2} / 2 V\right]
$$

with $V=V_{E 1}(\alpha+\beta) / \beta, \alpha=g_{2}\left[g_{2}\left(g_{2}+V_{E 1}\right)+V_{E 2}\right] / V_{E 1} V_{E 2}$, and $\beta=\left[g_{2}\left(g_{2}+\right.\right.$ $\left.\left.V_{E 1}\right) / V_{E 2}\right]+2$, provided that $\alpha$ is greater than 5 . Thus, for these conditions, $w\left(g_{1}, g_{2} \mid \phi\right)$ is approximately normal with optimal environment $g_{1}$ and breadth of adaptation $V^{1 / 2}$. The necessary conditions for this normal approximation may not be very restrictive. If we adopt a scale such that $V_{E 1}=1$, as we do in the following analyses, then the criterion that $\alpha$ is greater than 5 will be met if $g_{2}$ is greater than approximately 1.0 and the coefficient of variation, $V^{1 / 2}{ }_{E 2} / g_{2}$, is less than approximately 1.0. Coefficients of variation in excess of 1.0 are extremely unusual for polygenic traits (Falconer 1981), and our following results suggest that a $g_{2}$ less than 1.0 is unlikely to persist in any environment exhibiting variability. 


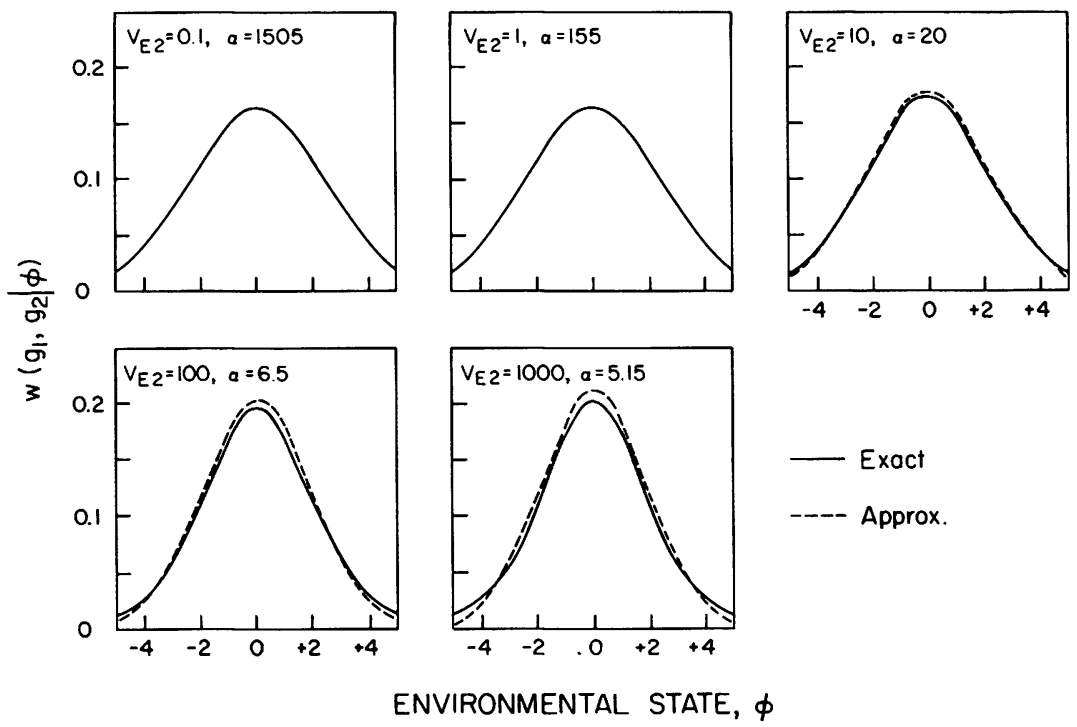

FIG. 1.-The influence of $V_{E 2}$ on the genotypic tolerance curve and the degree of correspondence between the "exact" and approximate solutions for $w\left(g_{1}, g_{2} \mid \phi\right)$, equations (A4) and (A7). The "exact" solutions were obtained by using a five-term Sterling's approximation (Abramowitz and Stegun 1972, eq. 6.1.37) for the gamma functions and expanding the confluent hypergeometric function to 40 terms. The two solutions are indistinguishable on a graph for the cases of $V_{E 2}=0.1$ and 1.0. In all cases, $g_{1}=0, g_{2}=5$, and $V_{E 1}=1$.

Equation 6 shows that the two types of developmental noise have opposite effects on $w\left(g_{1}, g_{2} \mid \phi\right)$. Although variance in the environmental optimum $\left(V_{E 1}\right)$ results in a broadening of the genotypic tolerance curve, $V_{E 2}$ causes it to narrow. The latter effect is not a peculiar property of the function for $p\left(z_{2} \mid g_{2}\right)$ that we have adopted in this paper (Lynch and Gabriel 1986). In the limiting case in which $V_{E 2}$ $=0$, equation (6) applies exactly and the realized breadth of adaptation is $V^{1 / 2}=$ $\left(g_{2}+V_{E 1}\right)^{1 / 2}$. At the limit of applicability of equation (6) $\left(g_{2} \geq 1\right.$ and $V^{1 / 2}{ }^{1 /} / g_{2}=$ $1.0), V^{1 / 2} \simeq\left[\left(2 g_{2} / 3\right)+V_{E 1}\right]^{1 / 2}$. For still larger $V_{E 2}$, the exact solution of equation (3) shows that the genotypic tolerance curve becomes significantly leptokurtic, that is, narrower and more peaked near $\phi=g_{1}$ with elevated fitness in environments with extreme $\phi$ (fig. 1). Thus, depending on the relative levels of $V_{E 1}$ and $V_{E 2}$, the equitability of a clone's fitness over environmental states, that is, its realized breadth of adaptation, may be magnified or reduced relative to expectations based on its actual genetic attribute $g_{2}$.

\section{Spatial and Temporal Heterogeneity within a Generation}

We next consider the role that some general selective forces may play in the evolution of tolerance curves. We will not consider selection-mutation balance or other equilibrium conditions for the maintenance of genetic variance for $g_{1}$ and $g_{2}$. Our concern will simply be to identify the tolerance curve that maximizes the mean fitness of a clone exposed to spatial and temporal environmental variation.

In a spatially and temporally uniform setting with environmental state $\phi$, equa- 
tion (6) would define the fitness of genotype $\left(g_{1}, g_{2}\right)$. The optimal genotype under such circumstances would clearly be the extreme specialist with optimal environmental state $g_{1}=\phi$ and with the minimum possible $g_{2}$. Since such environments are biologically unrealistic, however, it is essential to determine how spatial and temporal variation in $\phi$ may influence the outcome of clonal selection operating on the tolerance curve. Let us first evaluate the consequences of within-generation spatial and temporal variance.

For a population growing in discrete generations, a mean environmental state, $\phi_{t}$, may be identified for each generation $t$. If the environment is spatially complex, then it is likely that the mean environmental state experienced by each individual $\left(\phi_{s}\right)$ will deviate somewhat from $\phi_{t}$. We assume that $\phi_{s}$ is normally distributed about $\phi_{t}$ with variance $V_{\phi s}$ so that

$$
p\left(\phi_{s} \mid \phi_{t}\right)=\left(2 \pi V_{\phi s}\right)^{-1 / 2} \exp \left[-\left(\phi_{s}-\phi_{t}\right)^{2} / 2 V_{\phi s}\right] .
$$

We emphasize that $V_{\phi s}$ is a measure of spatial heterogeneity perceived by a population, not an intrinsic property of the environment. It is likely that $V_{\phi s}$ will be higher for a sedentary species than for a mobile species and that habitat selection will result in a further reduction in $V_{\phi s}$.

We incorporate within-generation temporal variance by allowing the environmental state experienced by each individual to be temporally distributed about $\phi_{s}$ with variance $V_{\phi r w}$. An implicit assumption in such a treatment is that all microhabitats experience the same level of temporal heterogeneity. The expected fitness of genotype $\left(g_{1}, g_{2}\right)$ in generation $t$ is then the arithmetic mean of the $\phi_{s^{-}}$ dependent fitnesses weighted by the probability of the occurrence of $\phi_{s}$. We assume that temporal variation in $\phi$ influences the fitness of a clone geometrically (as when daily probabilities of survival interact multiplicatively to give annual survival),

$$
w\left(g_{1}, g_{2} \mid \phi_{t}\right)=\int_{-\infty}^{+\infty} p\left(\phi_{s} \mid \phi_{t}\right)\left\{\left[\prod_{i=1}^{\tau} w\left(g_{1}, g_{2} \mid \phi_{s}\right)_{i}\right]^{1 / \tau}\right\} d \phi_{s},
$$

where $\tau$ is the number of discrete time steps of equal length per generation. The $w\left(g_{1}, g_{2} \mid \phi_{s}\right)_{i}$ may be thought of as the multiplicative components of fitness in the life cycle. The item in braces, which is the lifetime fitness of genotype $\left(g_{1}, g_{2}\right)$ in a habitat of mean state $\phi_{s}$ in generation $t$, may be abbreviated as $w\left(g_{1}, g_{2} \mid \phi_{s}\right)_{t}$. From equation (6),

$$
w\left(g_{1}, g_{2} \mid \phi_{s}\right)_{t}=(2 \pi V)^{-1 / 2} \exp \left[-\sum_{i=1}^{\tau}\left(g_{1}^{2}-2 g_{1} \phi_{s i}+\phi_{s i}^{2}\right) / 2 \tau V\right],
$$

where $\phi_{s i}$ represents the environmental state experienced at time $i$. Assuming large $\tau$ and noting that $\mathrm{E}\left(\phi_{s i}^{2}\right)=\phi_{s}^{2}+V_{\phi t w}$, this further reduces to

$$
w\left(g_{1}, g_{2} \mid \phi_{s}\right)_{t}=(2 \pi V)^{-1 / 2} \exp \left\{-\left[\left(g_{1}-\phi_{s}\right)^{2}+V_{\phi t w}\right] / 2 V\right\},
$$

which upon substitution in equation (8) yields

$$
\begin{aligned}
w\left(g_{1}, g_{2} \mid \phi_{t}\right)= & {\left[2 \pi\left(V+V_{\phi s}\right)\right]^{-1 / 2} \exp \left\{-1 / 2\left[\left(V_{\phi t w} / V\right)\right.\right.} \\
& \left.\left.+\left(g_{1}-\phi_{t}\right)^{2} /\left(V+V_{\phi s}\right)\right]\right\} .
\end{aligned}
$$




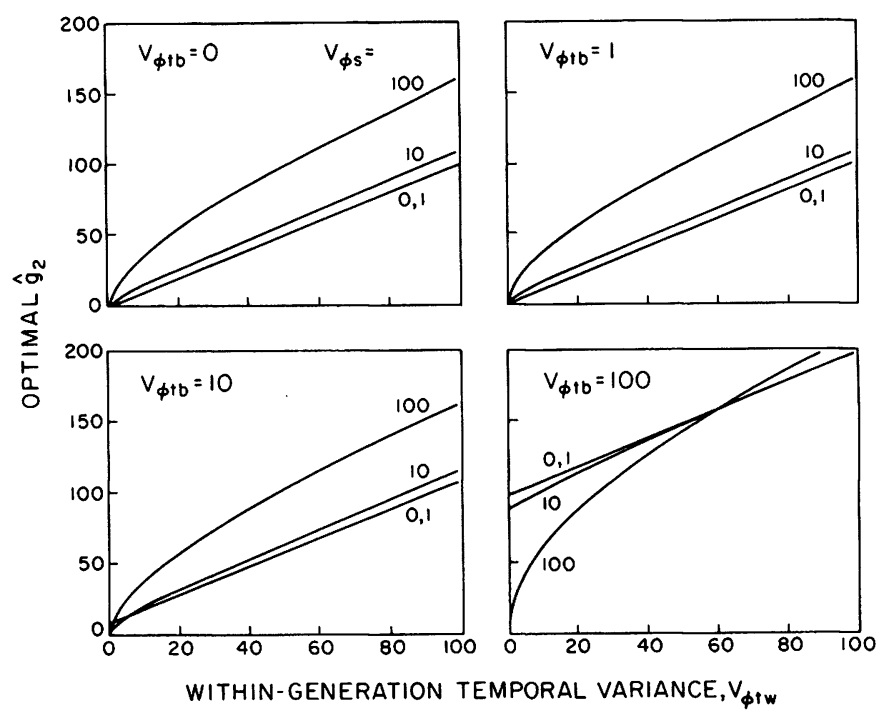

FIG. 2.-The optimal genetic parameter $\hat{g}_{2}$ for the case in which $V_{E 2}=0, g_{1}=\phi_{t}$, and $V_{E 1}$ $=1$. Since $\hat{g}_{2}=\hat{V}-1$ in this case, the optimal value of $\hat{V}$ for any combination of $V_{\phi s}, V_{\phi t w}$, and $V_{\phi t b}$ can be taken from these graphs as $\hat{g}_{2}+1$. The influence of $V_{E 2}$ on $\hat{g}_{2}$ is obtainable from the definition of $V$ in the text by back substitution.

This is the expected fitness of a clone with properties $\left(g_{1}, g_{2}\right)$ in generation $t$. Note that in the derivation of equation (9) no assumptions were made about the temporal autocorrelation of fitness variation.

Equation (9) indicates that spatial heterogeneity alone is insufficient to discourage the evolution of specialization in an asexual population. In the absence of temporal variance in $\phi$, the most-fit clones in each generation will be those with the minimum values for $\left|g_{1}-\phi_{t}\right|$ and $g_{2}$. Nevertheless, since $V_{\phi s}$ contributes to the breadth of $w\left(g_{1}, g_{2} \mid \phi_{t}\right)$, spatial heterogeneity can impede the rate at which the most specialized clones come to dominate by reducing the fitness differential between clones. However, within-generation temporal variation in $\phi$ encourages the evolution of generalism. The optimal realized breadth of adaptation is obtained by taking the derivative $d w\left(g_{1}, g_{2} \mid \phi_{t}\right) / d V$, and setting it and $\left(g_{1}-\phi_{t}\right)$ equal to zero,

$$
\hat{V}^{1 / 2}=\left\{1 / 2 V_{\phi t w}+1 / 2\left[V_{\phi t w}\left(V_{\phi t w}+4 V_{\phi s}\right)\right]^{1 / 2}\right\}^{1 / 2} .
$$

Some degree of generalization at the genetic level $\left(\hat{g}_{2}>0\right)$ will be favored provided that $V_{\phi \ell w}>V_{E 1}^{2} /\left(V_{\phi s}+V_{E 1}\right)$. This follows from setting $\hat{V}=\hat{g}_{2}+V_{E 1}$ or $=2 \hat{g}_{2} / 3+V_{E 1}$, the limits to the applicability of the approximation (9), and solving for the conditions for $\hat{g}_{2}>0$. Since $V_{E 1}$ contributes positively to $\hat{V}$, developmental noise for a clone's optimal environment causes a decrease in $\hat{g}_{2}$. This result arises because a large $V_{E 1}$ allows the members of a clone to exploit a diversity of environments without the cost of evolving generalism.

Figure 2 (upper left panel) illustrates the dependence of $\hat{g}_{2}$ on $V_{\phi s}$ and $V_{\phi t w}$ for the special case in which $V_{E 2}=0$, with the scale set so that $V_{E 1}=1$. Since $V$ declines from $g_{2}+V_{E 1}$ to approximately $2 g_{2} / 3+V_{E 1}$ as $V_{E 2}^{1 / 2} / g_{2}$ increases from 0 
to 1, the effect of $V_{E 2}$ within this range will be to increase $\hat{g}_{2}$ by a factor of $50 \%$ at the most. Thus, provided that $V^{1 / 2}{ }_{E 2} / g_{2}$ is within the range commonly observed for metric characters $\left(0.1-0.5\right.$; Falconer 1981) and that $V_{\phi s}$ is less than approximately $10 V_{E 1}$, then $\hat{g}_{2}$ is approximately equal to $V_{\phi t w}$; that is, the optimal breadth of adaptation is expected to increase linearly with the square root of the temporal variance of $\phi$. Only when $V_{\phi s}$ is greater than $10 V_{E 1}$ does spatial heterogeneity promote a more discernible increase in $\hat{g}_{2}$. The interactive effect of spatial and temporal heterogeneity on $\hat{g}_{2}$ arises because of the nonlinear nature of the Gaussian tolerance curve. Whereas $V_{\phi t w}$ results in a net reduction in fitness for individuals in environments with $\phi_{s}$ near $g_{1}$, in more extreme environments $w\left(g_{1}, g_{2} \mid \phi_{t}\right)$ is concave upward and temporal fluctuations in $\phi$ can actually enhance an individual's fitness.

\section{LONG-TERM GEOMETRIC-MEAN FITNESS}

Finally, we incorporate the between-generation component of temporal variance in the environmental state by letting $\phi_{t}$ be distributed with variance $V_{\phi t b}$ and scaled such that the long-term mean environmental state $\left(\phi_{t}\right)$ is zero. Dempster (1955) showed that in asexual populations, in the absence of the opposing forces of mutation, migration, and drift, the clone with the maximum geometric-mean fitness always approaches fixation asymptotically. Thus, the appropriate fitness measure is now the expected geometric-mean fitness of genotype $\left(g_{1}, g_{2}\right)$,

$$
w\left(g_{1}, g_{2}\right)=\lim _{T \rightarrow \infty}\left[\prod_{t=1}^{T} w\left(g_{1}, g_{2} \mid \phi_{t}\right)\right]^{1 / T} .
$$

Substituting equation (9) and taking expectations, we find

$$
\begin{aligned}
w\left(g_{1}, g_{2}\right)= & {\left[2 \pi\left(V+V_{\phi s}\right)\right]^{-1 / 2} \exp \left\{-1 / 2\left[V_{\phi t w} / V\right.\right.} \\
& \left.\left.+\left(g_{1}^{2}+V_{\phi t b}\right) /\left(V+V_{\phi s}\right)\right]\right\} .
\end{aligned}
$$

In the derivation of equation (11) we have assumed that $V_{\phi s}$ and $V_{\phi t w}$ are constant between generations, but again we have made no assumptions about the temporal pattern of $\phi_{t}$. A simple analytical solution of equation (11) for $\hat{g}_{2}$ cannot be obtained. It can be shown by differentiation, however, that between-generation temporal variance in $\phi$ always elevates $\hat{g}_{2}$ above that expected for environments with constant $\phi_{t}$. Moreover, it can be seen from equation (11) that $V_{\phi t b}$ and $V_{\phi t w}$ have identical influences on genotypic fitness, and hence on $\hat{g}_{2}$, in spatially homogeneous environments $\left(V_{\phi s}=0\right)$. The significance of $V_{\phi t b}$ is diminished in spatially heterogeneous environments because a relatively uniform distribution of possible environmental states is already present and a change in the mean environmental state between generations does little to change the distribution.

Figure 2 shows that because increasing $V_{\phi t b}$ causes $\hat{g}_{2}$ to increase and because the effect is magnified in spatially homogeneous environments, an inverse relationship can sometimes arise between $V_{\phi s}$ and $\hat{g}_{2}$ if $V_{\phi t w}$ is less than approximately $V_{\phi t b} / 3$. This result arises in environments that are spatially and temporally uniform 
within generations because most members of a clone suffer equally in extreme generations and persistence can only be accomplished by a generalist strategy. In a more spatially complex setting, even for generations in which $\left(g_{1}-\phi_{t}\right)$ is extreme, there are always some spatial refugia and the cost of evolving generalism can be partially avoided.

\section{METHODOLOGICAL CONSIDERATIONS}

We now turn our attention from theoretical matters to some of the practical problems that must be considered when applying tolerance-curve theory to natural populations. Parameters of the tolerance curve are qualitatively different from most quantitative traits studied by evolutionary biologists in that the former can never be estimated with single individuals. Since the fitness of an organism can only be measured once, determining the width and location of the peak of the genotypic tolerance curve requires genotypes that can be replicated exactly and grown in different environments. Thus, the implementation of our theory in a genetic analysis is possible only with organisms that can be propagated by asexual means. This does not rule out the analysis of sexual populations, however, since many sexual organisms can also reproduce vegetatively.

In principle, the distribution of a genotype's fitness over a continuous environmental gradient can be determined in the field by monitoring individuals and their respective environmental states. This, of course, requires that members of individual genotypes can be identified with certainty. Alternatively, members of a known genotype can be grown in a number of discrete environmental states in the laboratory, glasshouse, or experimental plots. Special precautions are always necessary in a field setting, where the states of different environmental gradients may not be independent of each other, in which case recourse to a multivariate analysis might be necessary.

Given that the appropriate data are obtainable, the problem is to translate the individual estimates of fitness and environmental state into the parameters $g_{1}, g_{2}$, $V_{E 1}$, and $V_{E 2}$. Provided that the developmental deviations, $e_{1}$, are symmetrically distributed around $g_{1}$, then $g_{1}$ simply equals the location of the peak of the fitness function. As noted above, however, the "variance" of the distribution of fitness on $\phi$ is not an estimator of $g_{2}$, but a complicated function of $g_{2}, V_{E 1}$, and $V_{E 2}$. Nevertheless, when certain assumptions are met, statistical models can be derived that allow the resolution of the moments of the genotypic tolerance curve into estimates of $g_{2}, V_{E 1}$, and $V_{E 2}$.

We offer the following analytical techniques for use when the assumptions of the models presented in the preceding section are met. That is, we assume that $\phi$ is measured on a scale such that $w\left(z_{1}, z_{2} \mid \phi\right)$ is normal and that the developmental deviations $e_{1}$ and $e_{2}$ are approximately normally and independently distributed. These conditions will not have been met if the observed tolerance curve is asymmetrical, that is, if any of the odd moments of $w\left(g_{1}, g_{2} \mid \phi\right)$ are significant, or if $w\left(g_{1}, g_{2} \mid \phi\right)$ is significantly leptokurtic. Our assumptions of normality can be relaxed, and alternative models derived, but there is little point in pursuing this matter until the relevant data have been obtained. Our primary point is to demon- 
strate that since the estimates of $g_{1}, g_{2}, V_{E 1}$, and $V_{E 2}$ are obtainable in principle, the theoretical expectations generated above are testable.

The estimation procedure is quite routine for determining a genotype's environmental optimum $\left(g_{1}\right)$ and realized breadth of adaptation $\left(V^{1 / 2}\right)$ without regard to the underlying mechanisms. We have noted above that when the conditional phenotype distributions, $p\left(z_{1} \mid g_{1}\right)$ and $p\left(z_{2} \mid g_{2}\right)$, are approximately normal, the expected genotypic tolerance curve will also be normal. The first two moments $\left(m_{1}\right.$ and $\left.m_{2}\right)$ of this fitness distribution over $\phi$ provide the desired information:

$$
\begin{gathered}
g_{1} \simeq m_{1}=\sum_{i=1}^{n} w_{i} \phi_{i} / \sum_{i=1}^{n} w_{i}, \\
V \simeq m_{2}=\sum_{i=1}^{n} w_{i}\left(\phi_{i}-m_{1}\right)^{2} / \sum_{i=1}^{n} w_{i},
\end{gathered}
$$

where $w_{i}$ and $\phi_{i}$ are the fitness and environmental-state measures for the $i$ th individual, and a total of $n$ individuals are evaluated. These equations apply when individuals are evenly sampled from all environments over the gradient. When such a protocol cannot be followed, $\phi_{i}$ should be the $i$ th environmental state and $w_{i}$ the mean fitness of individuals in that environment. Following Kendall and Stuart $\left(1977\right.$, p. 245), the sampling variances for $g_{1}$ and $V$ are approximately $\operatorname{var}\left(g_{1}\right)=m_{2} / n$ and $\operatorname{var}(V)=\left(m_{4}-m_{2}^{2}\right) / n$, where

$$
m_{4}=\sum_{i=1}^{n} w_{i}\left(\phi_{i}-m_{i}\right)^{4} / \sum_{i=1}^{n} w_{i} .
$$

In many situations, such as toxicity testing, $V^{1 / 2}$ provides adequate information on the breadth of adaptation. When gathered in conjunction with estimates of $V_{\phi s}$, $V_{\phi t w}$, and $V_{\phi t b}$, estimates of $V^{1 / 2}$ from different genotypes are also adequate to test much of the theory that we have developed above, because the genotypic property $g_{2}$ is expected to evolve subject to the constraint that $V$ is optimized.

However, in order to test our idea that $V_{E 1}$ and $V_{E 2}$ influence the optimal $g_{2}$, a more discriminating procedure is required to separate the effects of $g_{2}, V_{E 1}$, and $V_{E 2}$ on the breadth of adaptation. The basis for such an analysis is the influence that $V_{E 1}$ and $V_{E 2}$ have on the shape of the sampling distribution around the expected genotypic tolerance curve (fig. 3). In some cases, the patterns may be striking enough that a prognosis of the relative importance of $V_{E 1}$ and $V_{E 2}$ can be reached by examination of the distribution of $\left(w_{i}, \phi_{i}\right)$ in a scatter plot. When the variance in $z_{1}$ predominates (fig. 3c), a flat and narrow distribution of points appears around the environmental optimum. When the variance in $z_{2}$ predominates (fig. $3 b$ ), a narrow band of points appears near $g_{1} \pm\left(g_{2}\right)^{1 / 2}$.

We have attempted to exploit this information in a number of ways to generate estimates of the four parameters $\left(g_{1}, g_{2}, V_{E 1}, V_{E 2}\right)$ and have settled on the maximum-likelihood method as the most expedient approach. Suppose measures of fitness $\left(w_{i}\right)$ and environmental state $\left(\phi_{i}\right)$ have been obtained for $n$ individuals. The strategy of the maximum-likelihood procedure is to estimate the values of $g_{1}$, $g_{2}, V_{E 1}$, and $V_{E 2}$ that maximize the joint probability of all of the observations of 


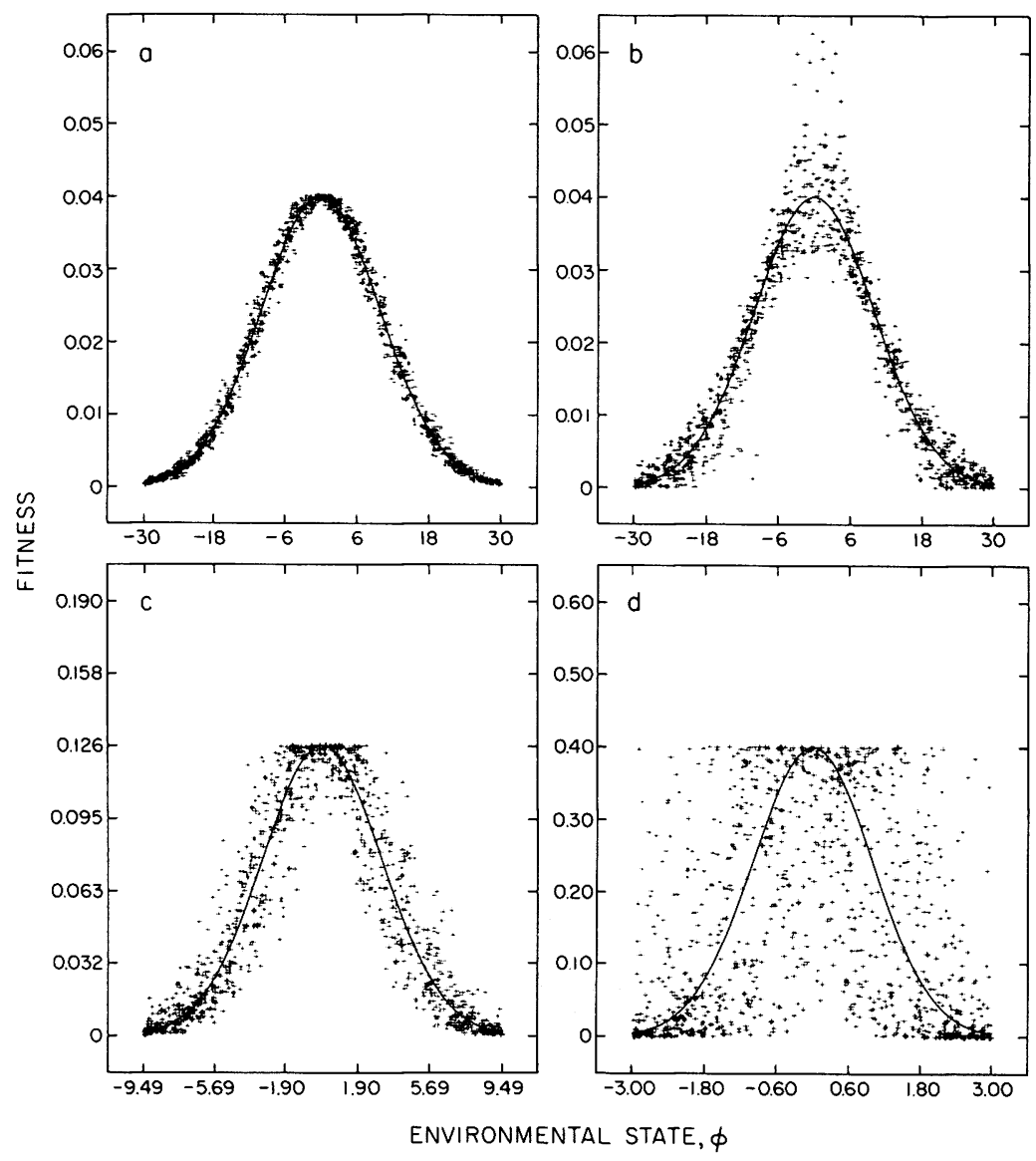

Fig. 3.-Examples of the expected sampling distribution of fitness over an environmental gradient. In each case, 1000 phenotypes were randomly drawn according to equations (5) and (A2) and randomly assigned an environmental state $\phi$, yielding a fitness estimate defined by equation (1). In all cases, $g_{1}=0$ and $V_{E 1}=1$. $a, g_{2}=100, V_{E 2}=1 ; b, g_{2}=1000, V_{E 2}=$ $1000 ; c, g_{2}=10, V_{E 2}=0 ; d, g_{2}=1, V_{E 2}=0$. Solid line, The expected fitness function for the deterministic situation in which $V_{E 1}=V_{E 2}=0$.

$\left(w_{i}, \phi_{i}\right)$. Letting $p_{i}$ be the a posteriori probability of the observation $\left(w_{i}, \phi_{i}\right)$ conditional on estimates of $g_{1}, g_{2}, V_{E 1}$, and $V_{E 2}$, methods of numerical mathematics can be used to obtain the solution that maximizes $\prod_{i=1}^{n} p_{i}$ provided that a function for $p_{i}$ is available.

There are several advantages to such an estimation procedure. It not only generates a joint solution for the four unknown parameters, but also yields the sampling variances. Measures of fitness over the entire range of $\phi$ are not essential for the procurement of accurate parameter estimations. The model can be used to analyze data sets in which multiple estimates of $w_{i}$ are available in a few environments with fixed $\phi$ or data sets in which $\phi_{i}$ is essentially different for all individuals. Although maximum-likelihood estimation does require considerable compu- 


\section{TABLE 1}

A Comparison of Maximum-Likelihood Estimates of the Tolerance-Curve Parameters $g_{2}, V_{E 1}$, AND $V_{E 2}$ WITH KNOWN VALUES

\begin{tabular}{|c|c|c|c|c|c|c|}
\hline & $g_{2}$ & $V_{E 1}$ & $V_{E 2}$ & $g_{2}$ & $V_{E 1}$ & $V_{E 2}$ \\
\hline True value & 4.000 & 1.000 & 1.600 & 1.000 & 0.250 & 0.100 \\
\hline $\begin{array}{l}\text { Maximum-likelihood } \\
\text { estimates }\end{array}$ & $\left\{\begin{array}{l}3.815 \\
4.505 \\
4.700\end{array}\right.$ & $\begin{array}{l}1.214 \\
0.836 \\
0.921\end{array}$ & $\begin{array}{l}0.808 \\
1.515 \\
1.568\end{array}$ & $\left\{\begin{array}{l}0.954 \\
1.115 \\
1.169\end{array}\right.$ & $\begin{array}{l}0.304 \\
0.277 \\
0.226\end{array}$ & $\begin{array}{l}0.050 \\
0.107 \\
0.094\end{array}$ \\
\hline True value & 10.000 & 1.000 & 1.000 & 5.000 & 1.000 & 3.000 \\
\hline $\begin{array}{l}\text { Maximum-likelihood } \\
\text { estimates }\end{array}$ & $\left\{\begin{array}{r}9.964 \\
10.592 \\
10.306\end{array}\right.$ & $\begin{array}{l}1.224 \\
0.784 \\
1.052\end{array}$ & $\begin{array}{l}0.822 \\
1.202 \\
1.088\end{array}$ & $\begin{array}{l}5.744 \\
5.502 \\
5.198\end{array}$ & $\begin{array}{l}1.099 \\
1.087 \\
0.652\end{array}$ & $\begin{array}{l}3.217 \\
3.298 \\
0.853\end{array}$ \\
\hline $\begin{array}{l}\text { True value } \\
\text { Maximum-likelihood } \\
\text { estimates }\end{array}$ & $\begin{array}{l}1.000 \\
0.984 \\
0.985 \\
0.926\end{array}$ & $\begin{array}{l}0.250 \\
0.186 \\
0.264 \\
0.228\end{array}$ & $\begin{array}{l}0.010 \\
0.014 \\
0.020 \\
0.005\end{array}$ & & & \\
\hline
\end{tabular}

NotE.-It is assumed in these examples that accurate estimates of $g_{1}$, which equals zero, are available before the analysis. In each example, random values of $w_{i}$ and $\phi_{i}$ were obtained for 40 individuals in each of five environmental states, subject to the constraint that $z_{1}$ and $z_{2}$ are normally distributed (a close approximation in the case of $z_{2}$ ). For each set of known parameter values, three separate analyses of 200 different individuals were performed.

tational time, this is no longer a serious problem for laboratories possessing a microcomputer.

A derivation of the function $p_{i}$ for the special case in which an individual experiences a constant level of $\phi$ throughout its life and $\alpha$ is less than 5 is presented by Gabriel (1986). Such a function is most relevant for situations in which individuals are grown in a controlled environment at fixed $\phi$, as is often done in laboratory toxicity tests or in glasshouse gradient experiments. (In principle, using the equations we presented in the preceding section, $p_{i}$ can also be derived for situations in which $V_{\phi t w}>0$.) We tested the maximum-likelihood model by randomly drawing individuals of phenotype $\left(z_{1}, z_{2}\right)$ according to the distributions $p\left(z_{1} \mid g_{1}\right)$ and $p\left(z_{2} \mid g_{2}\right)$ and assigning them an environmental state $\phi_{i}$ and fitness $w_{i}$ defined by equation (1). The maximum-likelihood estimates of $g_{1}, g_{2}$, $V_{E 1}$, and $V_{E 2}$ were then compared with the known parameters of $p\left(z_{1} \mid g_{1}\right)$ and $p\left(z_{2} \mid g_{2}\right)$. Table 1 illustrates the accuracy of this estimation procedure. With a total sample size of 200 individuals assorted among 5 environmental states, the maximum-likelihood estimates are generally quite close to the known values. (The algorithm for this maximum-likelihood procedure may be obtained from W. Gabriel.)

Ultimately, for a complete analysis of the tolerance curve from the standpoint of a population, it is useful to know not only the levels of $V_{E 1}$ and $V_{E 2}$, but also the amount of genetic variance for the two tolerance-curve parameters, $V_{G 1}$ and $V_{G 2}$. This is clearly necessary in order to evaluate the sensitivity of a population to environmental extremes. Such an analysis is also required for a determination of the potential evolutionary response of a population's mean optimal environmental state and the breadth of adaptation caused, for example, by selective challenges resulting from changes in $\bar{\phi}, V_{\phi s}, V_{\phi t w}$, and/or $V_{\phi t b}$. 
In principle, the population parameters $\bar{g}_{1}, \bar{g}_{2}, V_{T 1}=V_{G 1}+V_{E 1}$, and $V_{T 2}=V_{G 2}$ $+V_{E 2}$ can be derived by the same procedures outlined above. It is not a small task, however. Once mean estimates have been obtained for $V_{E 1}$ and $V_{E 2}$ by analyzing several unique genotypes, a population of mixed genotypes may be evaluated over the environmental gradient. The environmental optimum for such a mixed population is $\bar{g}_{1}$. Provided that genotype-environment covariance is negligible and that the joint influence of genetic and environmental effects on $z_{1}$ and $z_{2}$ results in distributions of the form of equations (5) and (6), the maximumlikelihood method can be used, the estimated parameters now being $\bar{g}_{2}, V_{T 1}$, and $V_{T 2}$ instead of $g_{2}, V_{E 1}$, and $V_{E 2}$. By subtraction of the independently derived estimates of $V_{E 1}$ and $V_{E 2}$ from $V_{T 1}$ and $V_{T 2}$, the genetic variances and hence the broad-sense heritabilities (total genetic variance divided by phenotypic variance) of the tolerance-curve parameters may be obtained. Such an analysis requires that the genotypes be randomly distributed among environments, but again it is not necessary to investigate the entire range of $\phi$. Of course, if one is simply interested in the population properties $\bar{g}_{1}, \bar{g}_{2}, V_{T 1}$, and $V_{T 2}$, then it is unnecessary to perform a complete analysis on any individual genotypes (since estimates of $V_{E 1}$ and $V_{E 2}$ are not required).

\section{DISCUSSION}

We have shown that in the context of an evolutionary analysis of tolerance curves at least five kinds of environmental variance $\left(V_{E 1}, V_{E 2}, V_{\phi s}, V_{\phi t w}\right.$, and $\left.V_{\phi t b}\right)$ must be considered. Whereas any kind of temporal variance in the environment selects for more-broadly-adapted genotypes, temporal variance within generations $\left(V_{\phi t w}\right)$ plays a more important role than that between generations $\left(V_{\phi t b}\right)$, which becomes of negligible importance when the spatial component of variance is high. Spatial heterogeneity $\left(V_{\phi s}\right)$ caused by structural complexity or immobility of individuals also often selects for more-broadly-adapted genotypes, but only when it operates in conjunction with temporal variance. Moreover, when $V_{\phi t w}$ is much less than $V_{\phi t b}$, spatial heterogeneity can actually select for a higher degree of specialization.

In a more general way, $V_{\phi s}$ and $V_{\phi t w}$ can be considered the total variance in additive and multiplicative effects on fitness resulting from environmental heterogeneity. (This is how they were treated in the preceding derivations.) The use of $V_{\phi s}$ and $V_{\phi t w}$ also formalizes Levins' (1968) concept of environmental grain. In a fine-grained environment, an individual passes through many "patches" in its lifetime. This implies relatively low $V_{\phi s}$, since most individuals will experience most patch types during their lives, and relatively high $V_{\phi t w}$ resulting from the movement between different patches. In the most coarse-grained of environments, individuals spend their entire lives in single patches, thereby maximizing $V_{\phi s}$ but reducing $V_{\phi t w}$ to the temporal variance ambient in individual patches.

Elsewhere, from the standpoint of genic selection (Lynch and Gabriel 1986), we have pointed out that our results are not consistent with the verbal hypothesis of Ayala and Valentine (Ayala et al. 1975; Valentine 1976; Ayala and Valentine 1979), which implies a diminishing role for spatial heterogeneity in the selection 
process in temporally variable environments. Nevertheless, despite the complex ways in which different forms of environmental variability can interact, figure 1 illustrates the dominant role played by $V_{\phi t w}$ and suggests that, for clones taken from different environments, the relationship between $V$ and $V_{\phi t w}$ should have a slope between 1 and 2 if optimal $V$ is in fact strongly selected. As indicated in the figure, such a relationship would hold approximately even if the other variance parameters varied by one to two orders of magnitude.

If developmental influences $\left(V_{E 1}\right.$ and $\left.V_{E 2}\right)$ play a major role in determining an individual's optimal environmental state $\left(z_{1}\right)$ and breadth of adaptation $\left(z_{2}^{1 / 2}\right)$, then the realized breadth of adaptation $\left(V^{1 / 2}\right)$ for a genotype will often differ from that expected on the basis of genetic properties alone (i.e., $g_{2}{ }^{1 / 2}$ ). This need not always be the case, however. Because $V_{E 1}$ causes an increase in $V$ and $V_{E 2}$ causes a decrease, the two factors may sometimes counterbalance each other.

From the standpoint of the genotype, natural selection will tend to favor a $g_{2}$ subject to the constraint that $V$ is optimized. Thus, species for which $V_{\phi s}, V_{\phi t w}$, and $V_{\phi t b}$ are identical may be expected to evolve very different $g_{2}$ 's (while maintaining the same $V$ ) if interspecific variation in $V_{E 1}$ and $V_{E 2}$ is pronounced. Since $V_{E 1}$ and $V_{E 2}$ are functions of such physiological processes as acclimation ability and maternal effects and of developmental homeostasis, interspecific variation would not be surprising. It is also worth noting that such developmentalvariance components as $V_{E 1}$ and $V_{E 2}$ are not fixed properties of a genotype, but may be substantially modified depending on the environmental background of factors other than the one of interest (Falconer 1981). Thus, the realized breadth of adaptation of a genotype might be radically altered when it is transplanted to a new setting (Via and Lande 1985). Obviously, any attempt to interpret empirical estimates of $V_{E 1}$ and $V_{E 2}$ should consider this.

It is important to recognize that in analyzing for the optimal parameters $\left(\hat{g}_{1}, \hat{g}_{2}\right)$ of the tolerance curve, we have assumed a fixed trade-off between the maximum fitness of an individual and its breadth of adaptation (eqs. 1 and 2). This is not totally realistic since there must occasionally arise mutants, for which the integral in equation (2) (call it $k$ ) does not equal 1 . In that case, a clone with nonoptimal $\left(g_{1}, g_{2}\right)$ and $k$ greater than 1 could sometimes displace a clone with optimal $\left(g_{1}, g_{2}\right)$ and $k$ equal to 1 , since the former's fitness in all environments would be elevated by a factor of $k$ relative to the expressions given above. The outcome of such events can be assessed by comparing the solutions to equations such as (1), (6), (9), and (11): substitute the appropriate values of $g_{1}$ and $g_{2}$ for the two clones and multiply the mutant's fitness by $k$. If adaptive mutations for $k$ arise much more frequently than those for $g_{1}$ and $g_{2}$, natural populations may often appear to be "maladapted" with respect to the optimal environmental state and breadth of adaptation.

We have attempted to provide statistical procedures for parameter estimation such that the hypotheses generated by our model can be tested. The methodology that we recommend may also be of practical value in evaluating the sensitivity of genotypes and/or populations to environmental extremes, as is routinely done in assessments of environmental impacts and in the development of resistant varieties of economically important crops. A large number of reports in the literature already contain data on the relationship of partial or total fitness to physical and/or 
chemical parameters. Unfortunately, they do not state whether the types of patterns generated in figure 3 are often observed, since the mean estimates of fitness rather than the individual data points are always reported.

The theory we have developed demonstrates that a substantial amount of valuable information on the mechanisms underlying the breadth of adaptation is concealed when data are simply averaged. When sufficient data are obtained, the maximum-likelihood method has the power to identify the extent to which the breadth of adaptation of a population is caused by $g_{2}, V_{E 1}, V_{G 1}, V_{E 2}$, and $V_{G 2}$. Such information is essential if one wants to estimate the long-term flexibility of a population in the face of new selective challenges. Thus, the large pools of data generated by those in areas of applied ecology (and often filed away in laboratory notebooks or agency reports and ignored by those of us in less-applied research areas) may be of great value in gaining a deeper understanding of the adaptational aspects of environmental tolerance.

\section{SUMMARY}

A theory for the expression of a population's response to density-independent gradients of environmental factors is derived for the case of asexuality. It is shown that the environmental tolerance of a genotype is a function of at least four parameters: $g_{1}$ and $V_{E 1}$, the environmental optimum and its developmental variance between individuals, and $g_{2}$ and $V_{E 2}$, the expected genetic contribution to the breadth of adaptation and its developmental variance. The realized breadth of adaptation of a genotype $\left(V^{1 / 2}\right)$ is a complex function of $g_{2}, V_{E 1}$, and $V_{E 2}$, but we argue that, with an appropriate scale transformation, the tolerance curve of a genotype is approximately normal, with mean $g_{1}$ and standard deviation $V^{1 / 2}$. It is shown that temporal heterogeneity in the environment selects for more-broadlyadapted genotypes but that the within-generation component $\left(V_{\phi t w}\right)$ plays a more prominent role than the between-generation component $\left(V_{\phi t b}\right)$. Spatial heterogeneity selects for higher $V^{1 / 2}$ only when it occurs in conjunction with temporal variance within generations and only if $V_{\phi t b}$ is small relative to $V_{\phi t w}$. We argue that since $g_{2}$ is expected to evolve subject to the constraint that $V^{1 / 2}$ is optimized, species exposed to conditions favoring identical $V^{1 / 2}$ may evolve different $g_{2}$ if pronounced interspecific differences exist for $V_{E 1}$ and $V_{E 2}$.

A maximum-likelihood method is shown to be capable of generating accurate estimates of the genotypic parameters $g_{1}, g_{2}, V_{E 1}$, and $V_{E 2}$ with moderately large samples. We suggest how this procedure may be used to estimate analogous parameters for a population of mixed genotypes and to obtain estimates of the genetic variance for the environmental optimum and breadth of adaptation. The potential utility of this methodology for the analysis of data routinely generated in programs for environmental assessment and plant breeding is pointed out.

\section{ACKNOWLEDGMENTS}

We are very grateful to S. Portnoy for pointing out the utility of the beta distribution of the second kind, R. Bohrer for helpful suggestions, J. Gresey, A. Lee, and S. Schiller for analytical assistance, and J. Jacobs, V. Loeschcke, A. van 
Noordwijk, S. Via, and three anonymous reviewers for comments. Supported by National Science Foundation grants BSR 83-06072 and SUB U MICHX 98674 and fellowships from the Max Planck Society (M.L.).

\section{APPENDIX}

\section{Derivation of the Genotypic Tolerance Curve}

Because of the influence of environmental effects on phenotype, the many individuals of a given genotype generally form a continuum of phenotypes. If we define the fitness of a phenotype as a Gaussian function of two characters, $z_{1}$ (the optimal environmental state) and $z_{2}$ (where $z_{2}^{1 / 2}$ is the breadth of adaptation), such that

$$
w\left(z_{1}, z_{2} \mid \phi\right)=\left(2 \pi z_{2}\right)^{-1 / 2} \exp \left[-\left(z_{1}-\phi\right)^{2} / 2 z_{2}\right],
$$

where $\phi$ is a continuously distributed environmental state, then the genotypic tolerance curve is defined by

$$
w\left(g_{1}, g_{2} \mid \phi\right)=\int_{0}^{+\infty} \int_{-\infty}^{+\infty} w\left(z_{1}, z_{2} \mid \phi\right) p\left(z_{1} \mid g_{1}\right) p\left(z_{2} \mid g_{2}\right) d z_{1} d z_{2} .
$$

We take the conditional phenotype distribution for the environmental optimum to be normal, with mean $g_{1}$ and variance $V_{E 1}$,

$$
p\left(z_{1} \mid g_{1}\right)=\left(2 \pi V_{E 1}\right)^{-1 / 2} \exp \left[-\left(z_{1}-g_{1}\right)^{2} / 2 V_{E 1}\right] .
$$

For the conditional distribution of $z_{2}$, we seek a function of the form $p(x)=x^{\alpha-1}$ $(1+x)^{-(\alpha+\beta)} / B(\alpha, \beta)$, where $B(\alpha, \beta)=\Gamma(\alpha) \Gamma(\beta) / \Gamma(\alpha+\beta)$ is the beta function with $\Gamma$ representing the gamma function. This is a beta distribution of the second kind, and its moments about the origin are known to be

$$
\mathrm{E}\left(x^{n}\right)=B(\alpha+n, \beta-n) / B(\alpha, \beta)=\Gamma(\alpha+n) \Gamma(\beta-n) /[\Gamma(\alpha) \Gamma(\beta)]
$$

(Kendall and Stuart 1977, p. 163). The mean is therefore $\mathrm{E}(x)=\alpha /(\beta-1)$ and the variance $\operatorname{var}(x)=\alpha(\alpha+\beta-1) /\left[(\beta-1)^{2}(\beta-2)\right]$. In order to make $x$ dimensionless, we let it equal $z_{2} / V_{E 1}$. Then, by change of variable, we obtain

$$
p\left(z_{2} \mid g_{2}\right)=\left(z_{2} / V_{E 1}\right)^{\alpha-1}\left[1+\left(z_{2} / V_{E 1}\right)\right]^{-(\alpha+\beta)} /\left[V_{E 1} B(\alpha, \beta)\right] .
$$

The required conditions that the mean and variance of $p\left(z_{2} \mid g_{2}\right)$ be independent (i.e., that $\mathrm{E}\left(z_{2}\right)=g_{2}$ and $\left.\operatorname{var}\left(z_{2}\right)=V_{E 2}\right)$ are satisfied when

$$
\begin{gathered}
\alpha=g_{2}\left[g_{2}\left(g_{2}+V_{E 1}\right)+V_{E 2}\right] / V_{E 1} V_{E 2}, \\
\beta=g_{2}\left(g_{2}+V_{E 1}\right) / V_{E 2}+2 .
\end{gathered}
$$

$V_{E 1}$ serves only as a scaling factor in equation (A2) and does not influence the shape of the distribution; that is, if $V_{E 1}^{\prime}=k V_{E 1}$, then $z_{2}^{\prime}=k z_{2}, g_{2}^{\prime}=k g_{2}, V_{E 2}^{\prime}=k^{2} V_{E 2}$, and $p\left(z_{2}^{\prime} \mid g_{2}^{\prime}\right)=$ $p\left(z_{2} \mid g_{2}\right)$.

Equation (A1) is solved by first integrating over $z_{1}$ to obtain

$$
\begin{aligned}
w\left(g_{1}, g_{2} \mid \phi\right)= & {\left[V_{E 1}(2 \pi)^{-1 / 2} / B(\alpha, \beta)\right] . } \\
& \int_{0}^{+\infty} z_{2}^{\alpha-1}\left(z_{2}+V_{E 1}\right)^{-(\alpha+\beta+1 / 2)} \exp \left\{-\left(g_{1}-\phi\right)^{2} /\left[2\left(z_{2}+V_{E 1}\right)\right]\right\} d z_{2},
\end{aligned}
$$

which, by change of variable to $t=V_{E 1} /\left(z_{2}+V_{E 1}\right)$, becomes

$w\left(g_{1}, g_{2} \mid \phi\right)=\left[\left(2 \pi V_{E 1}\right)^{1 / 2} B(\alpha, \beta)\right]^{-1} \int_{0}^{1}(1-t)^{\alpha-1} t^{\beta-1 / 2} \exp \left[-\left(g_{1}-\phi\right)^{2} t /\left(2 V_{E 1}\right)\right] d t$. 
The integral may be expressed in terms of the confluent hypergeometric function (Abramowitz and Stegun 1972, eq. 13.2.1),

$$
\int_{0}^{1}(1-t)^{b-a-1} t^{\alpha-1} \exp (c t) d t=B(b-a, a) M(a, b, c),
$$

where $a=\beta+1 / 2, b=\alpha+\beta+1 / 2, c=-\left(g_{1}-\phi\right)^{2} / 2 V_{E 1}$, and

$$
\begin{aligned}
M(a, b, c) & =1+\frac{a c}{b}+\frac{(a)_{2} c^{2}}{(b)_{2} 2 !}+\ldots+\frac{(a)_{n} c^{n}}{(b)_{n} n !}+\ldots \\
(a)_{n} & =\Gamma(a+n) / \Gamma(a)
\end{aligned}
$$

(Abramowitz and Stegun 1972, eq. 13.1.2). Utilizing the transformation $M(a, b, c)=$ $\exp (c) M(b-a, b,-c)$ (Abramowitz and Stegun 1972, eq. 13.1.27), we obtain

$w\left(g_{1}, g_{2} \mid \phi\right)-\left(2 \pi V_{E 1}\right)^{-1 / 2}[B(\alpha, \beta+1 / 2) / B(\alpha, \beta)] M(b-a, b,-c) \exp \left[-\left(g_{1}-\phi\right)^{2} / 2 V_{E 1}\right]$.

Provided that $\alpha$ is large ( $\gg 1$ ), equation (A4) can be greatly simplified by using two approximations. First, since for these conditions $(b-a)_{n} \simeq \alpha^{n}$ and $(b)_{n} \simeq(\alpha+\beta)^{n}$ for the early terms in the convergent expansion $M(b-a, b,-c)$, the series closely approximates that of the exponential function, and therefore

$$
M(b-a, b,-c) \simeq \exp \left\{\alpha\left(g_{1}-\phi\right)^{2} /\left[V_{E 1}(\alpha+\beta)\right]\right\} .
$$

Second, the term containing the beta functions can be reduced by making use of Sterling's approximation for gamma of large $x$, which yields

$$
\Gamma(x) / \Gamma(x+1 / 2) \simeq[x /(x+1 / 2)]^{x} x^{-1 / 2} \exp ^{1 / 2} .
$$

From the definition of the base of natural logarithms, $\lim _{x \rightarrow \infty}[x /(x+1 / 2)]^{x}=\exp -1 / 2$, which yields the further simplification

Noting that

$$
\Gamma(x) / \Gamma(x+1 / 2) \approx x^{-1 / 2} .
$$

$$
B(\alpha, \beta+1 / 2) / B(\alpha, \beta)=\Gamma(\alpha+\beta) \Gamma(\beta+1 / 2) /[\Gamma(\beta) \Gamma(\alpha+\beta+1 / 2)]
$$

and substituting (A5) and (A6) into (A4), we obtain the approximation

$$
w\left(g_{1}, g_{2} \mid \phi\right) \simeq(2 \pi V)^{-1 / 2} \exp \left[-\left(g_{1}-\phi\right)^{2} / 2 V\right],
$$

where $V=V_{E 1}(\alpha+\beta) / \beta$.

Thus, provided that $\alpha$ is large, the genotypic tolerance curve is expected to be approximately normal, with optimal environment $g_{1}$ and breadth of adaptation $V^{1 / 2}$. In actuality, the exact solution (A3) demonstrates that although $w\left(g_{1}, g_{2} \mid \phi\right)$ is always symmetrical, it is also leptokurtic. However, the difference between approximations (A4) and (A7) is essentially undetectable for $\alpha$ greater than approximately 25 , and the normal approximation provides a good approximation for $\alpha$ even as small as 5 (fig. 1).

\section{LITERATURE CITED}

Abramowitz, M., and I. A. Stegun, eds. 1972. Handbook of mathematical functions. Dover, New York.

Ayala, F. J., and J. W. Valentine. 1979. Genetic variability in the pelagic environment: a paradox? Ecology 60:24-29.

Ayala, F. J., J. W. Valentine, and G. S. Zumwalt. 1975. An electrophoretic study of the Antarctic zooplankter Euphausia superba. Limnol. Oceanogr. 20:635-639. 
Bell, G. 1982. The masterpiece of nature: the evolution and genetics of sexuality. University of California Press, Berkeley.

Bulmer, M. G. 1972. The genetic variability of polygenic characters under optimizing selection, mutation, and drift. Genet. Res. 19:17-25.

1974. Density-dependent selection and character displacement. Am. Nat. 108:45-58.

1980. The mathematical theory of quantitative genetics. Oxford University Press, New York.

Christiansen, F. B., and V. Loeschcke. 1980. Evolution and intraspecific exploitative competition. I. One-locus theory for small additive gene effects. Theor. Popul. Biol. 18:297-313.

Dempster, E. R. 1955. Maintenance of genetic heterogeneity. Cold Spring Harbor Symp. Quant. Biol. 20:25-32.

Falconer, D. S. 1981. Introduction to quantitative genetics. Longman, New York.

Feldman, M. W., and L. L. Cavalli-Sforza. 1979. Aspects of variance and covariance analysis with cultural inheritance. Theor. Popul. Biol. 15:276-307.

Felsenstein, J. 1979. Excursions along the interface between disruptive and stabilizing selection. Genetics 93:773-795.

Gabriel, W. 1986. The use of computer simulation to evaluate the testability of a new fitness concept. In D. P. F. Möller, ed. Advances of system analysis. Vol. 2. System analysis of biological processes. Vieweg, Brunswick, Federal Republic of Germany (in press).

Gillespie, J. H. 1976. A general model to account for enzyme variation in natural populations. II. Characterization of the fitness function. Am. Nat. 110:809-821.

1978. A general model to account for enzyme variation in natural populations. V. The SASCFF model. Theor. Popul. Biol. 14:1-45.

1984. Pleiotropic overdominance and the maintenance of genetic variation in polygenic characters. Genetics 107:321-330.

Gillespie, J. H., and C. H. Langley. 1974. A general model to account for enzyme variation in natural populations. Genetics 76:837-848.

Haldane, J. B. S., and S. D. Jayakar. 1963. Polymorphism due to selection in varying direction. J. Genet. 58:237-242.

Karlin, S., and U. Lieberman. 1974. Random temporal variation in selection intensities: case of large population size. Theor. Popul. Biol. 6:355-382.

Kendall, M., and A. Stuart. 1977. The advanced theory of statistics. Vol. 1. Distribution theory. 4th ed. Macmillan, New York.

Kirkpatrick, M. 1982. Quantum evolution and punctuated equilibria in continuous genetic characters. Am. Nat. 119:833-848.

Lande, R. 1976. The maintenance of genetic variability by mutation in a polygenic character with linked loci. Genet. Res. 26:221-235.

Lande, R., and S. J. Arnold. 1983. The measurement of selection on correlated characters. Evolution 37:1210-1226.

Latter, B. D. H. 1970. Selection in finite populations with multiple alleles. II. Centripetal selection, mutation, and isoallelic variation. Genetics 66:165-186.

Levene, H. 1953. Genetic equilibrium when more than one ecological niche is available. Am. Nat. 87:311-313.

Levins, R. 1968. Evolution in changing environments. Princeton University Press, Princeton, N.J.

Lynch, M., and W. Gabriel. 1983. Phenotypic evolution and parthenogenesis. Am. Nat. 122:745-764. 1986. The evolution of breadth of biochemical adaptation. In P. Calow, ed. Evolutionary physiological ecology. Cambridge University Press, Cambridge (in press).

Matsuda, H., and T. Gojobori. 1979. Protein polymorphism and fluctuation of environments. Adv. Biophys. 12:53-99.

Maynard Smith, J., and R. Hoekstra. 1980. Polymorphism in a varied environment: how robust are the models? Genet. Res. 35:45-57.

O'Donald, P. 1970. Change of fitness by selection for a quantitative character. Theor. Popul. Biol. 1:219-232.

Odum, E. P. 1971. Fundamentals of ecology. Saunders, Philadelphia.

Parsons, P. A. 1983. The evolutionary biology of colonizing species. Cambridge University Press, Cambridge. 
Ricklefs, R. E. 1973. Ecology. 2d ed. Chiron, New York.

Robertson, A. 1956. The effect of selection against extreme deviants based on deviation or on homozygosis. J. Genet. 54:236-248.

Roughgarden, J. 1972. Evolution of niche width. Am. Nat. 106:683-718.

Schmalhausen, I. I. 1949. Factors of evolution: the theory of stabilizing selection. Blakiston, Philadelphia.

Shelford, V. E. 1913. Animal communities in a temperate America. University of Chicago Press, Chicago.

Slatkin, M. 1970. Selection and polygenic characters. Proc. Natl. Acad. Sci. USA 66:87-93.

1979. Frequency- and density-dependent selection on a quantitative character. Genetics 93:755-771.

1980. Ecological character displacement. Ecology 61:163-177.

Slatkin, M., and R. Lande. 1976. Niche width in a fluctuating environment-density-independent model. Am. Nat. 110:31-55.

Takahata, N. 1981. Genetic variability and rate of gene substitution in a finite population under mutation and fluctuating selection. Genetics 98:427-440.

Taper, M. L., and T. J. Case. 1985. Quantitative genetic models for the coevolution of character displacement. Ecology 66:355-371.

Templeton, A. R., and E. D. Rothman. 1978. Evolution in fine-grained environments. I. Environmental runs and the evolution of homeostasis. Theor. Popul. Biol. 13:340-355.

1981. Evolution in fine-grained environments. II. Habitat-selection as a homeostatic mechanism. Theor. Popul. Biol. 19:326-340.

Valentine, J. W. 1976. Genetic strategies of adaptation. Pages 78-94 in F. J. Ayala, ed. Molecular evolution. Sinauer, Sunderland, Mass.

Van Valen, L. 1965. Morphological variation and width of ecological niche. Am. Nat. 99:377-390.

Via, S., and R. Lande. 1985. Genotype-environment interaction and the evolution of phenotypic plasticity. Evolution 39:505-522.

Whittaker, R. H., and S. A. Levin, eds. 1975. Niche: theory and application. Dowden, Hutchinson, \& Ross, New York.

Woltereck, R. 1909. Weitere Untersuchungen über Artveränderung, speziell über das Wesen quantitatives Artunterschiede bei Daphnien. Verh. Dtsch. Zool. Ges. 1909:110-172.

Wright, S. 1968. Evolution and the genetics of populations. Vol. 1. Genetic and biometric foundations. University of Chicago Press, Chicago. 


\title{
THE AMERICAN NATURALIST
}

ISSN 0003-0147

\author{
Marcus W. Feldman, Editor \\ Paul R. Ehrlich, Senior Associate Editor \\ Harold A. Mooney, Senior Associate Editor \\ Jonathan Roughgarden, Senior Associate Editor \\ Peter M. Vitousek, Senior Associate Editor \\ Jean Doble McIntosh, Managing Editor
}

Manuscripts and editorial correspondence should be addressed to The Editor, The American Naturalist, Department of Biological Sciences, Stanford University, Stanford, California 94305. A page of advice to authors may be found in this issue. Copy editor: Teresa Carson; editorial assistant: Stephanie Wawrzynski.

Subscription to the journal does not require membership in the American Society of Naturalists. Subscriptions to The American Naturalist may be ordered from, and remittance should be made payable to, The American Naturalist, The University of Chicago Press, Journals Division, P.O. Box 37005, Chicago, Illinois 60637. Subscription rates, U.S.A.: institutions, 1 year $\$ 90.00$; individuals, 1 year $\$ 50.00$; students, 1 year $\$ 35.00$ (letter from professor must accompany subscription). Other countries: add $\$ 9.00$ for each year's subscription to cover postage. Single-copy rates: institutions, $\$ 7.50$; individuals, $\$ 4.25$. Japanese subscription agent: Kinokuniya Company Ltd. Reprinted volumes 1-10 available from Walter J. Johnson, Inc., 355 Chestnut Street, Norwood, New Jersey 07648. Volumes available in microfilm from University Microfilms, 300 North Zeeb Road, Ann Arbor, Michigan 48106; in microfiche from Johnson Associates, P.O. Box 1017, Greenwich, Connecticut 06830.

For change of address, please notify the Press and local postmaster immediately, providing both the old and new addresses. Allow four weeks for change. Postmaster: send address changes to The American Naturalist, The University of Chicago Press, Journals Division, P.O. Box 37005, Chicago, Illinois 60637.

Copyright beyond fair use: The code on the first page of an article in this journal indicates the copyright owner's consent that copies of the article may be made beyond those permitted by Sections 107 or 108 of the U.S. Copyright Law provided that copies are made only for personal or internal use, or for the personal or internal use of specific clients and provided that the copier pay the stated per-copy fee through the Copyright Clearance Center, Inc., Operations Center, P.O. Box 765, Schenectady, New York 12301. To request permission for other kinds of copying, such as copying for general distribution, for advertising or promotional purposes, for creating new collective works, or for resale, kindly write to Permissions Department, The University of Chicago Press, 5801 S. Ellis Avenue, Chicago, Illinois 60637.

Second-class postage paid at Chicago, Illinois, and at additional mailing office. (c) 1987 by The University of Chicago. PRINTED IN U.S.A. 


\section{INDEX TO VOLUME 129}

\section{Alphabetical Table of Contents of Authors}

Agur, Zvia, and Michel Kerszberg. The emergence of phenotypic novelties through progressive genetic change, 862

Akin, E. See L. Levine

Andelman, Sandy J. Evolution of concealed ovulation in vervet monkeys (Cercopithecus aethiops), 785

Antonovics, JANIS. The Evolutionary DysSynthesis: which bottles for which wine? 321

Armitage, Kenneth B. Do female yellowbellied marmots adjust the sex ratios of their offspring? 501

Avery, M. I. See C. M. Lessells

Barker, J. S. F. See Robert R. Sokal

Bazzaz, F. A. See E. G. Reekie

Beissinger, Steven R. Anisogamy overcome: female strategies in snail kites, 486

BeLSKY, A. J. The effects of grazing: confounding of ecosystem, community, and organism scales, 777

Bengtsson, JaN. Smaller zooplankton species are not superior in exploitative competition: a comment on Persson, 928

Berryman, Alan A. See Kenneth F. RAFFA

Blower, Sally, and Jonathan RoughgarDEN. Population dynamics and parasitic castration: a mathematical model, 730

Blythe, S. P. See W. W. Murdoch

Bothwell, J. L. See Mary F. Willson

Broekhoven, Louis. See John McA. Eadie

Bryant, Stephen H. See Jerry A. Coyne

Budelmann, B.-U. See Roger T. Hanlon

Buechner, M. See J. A. Stamps

Bull, J. J., C. Thompson, D. NG, and R. Moore. A model for natural selection of genetic migration, 143

Caley, M. Julian, and Thomas D. Nudds. Sex-ratio adjustment in Odocoileus: does local resource competition play a role? 452

Campbell, Diane R., and Nickolas M. WASER. The evolution of plant mating systems: multilocus simulations of pollen dispersal, 593

Carpenter, Stephen R., and James F. KITCHELl. The temporal scale of variance in limnetic primary production, 417

Clark, Andrew G. Senescence and the genetic-correlation hang-up, 932

Colgan, Patrick. See John McA. Eadie

Commito, John A. Polinices predation patterns and Mercenaria morphology models, 449

Connell, Joseph H. See Terence P. HUGHES

Coyne, Jerry A., Stephen H. Bryant, and Michael Turelli. Long-distance migration of Drosophila. 2. Presence in desolate sites and dispersal near a desert oasis, 847

Craig, Catherine $L$. The significance of spider size to the diversification of spider-web architectures and spider reproductive modes, 47

Crump, Martha L. See Gary K. Meffe

Cwynar, Les C., and Glen M. MacDoNALD. Geographical variation of lodgepole pine in relation to population history, 463

Davis, L. E. See J. A. Winsor

Davis, Russell, and Christopher DunFORD. An example of contemporary colonization of montane islands by small, nonflying mammals in the American Southwest, 398

DeAngelis, D. L. See M. A. Huston

DE la Rosa, M. E. See L. Levine

Dhondt, André A. Polygynous blue tits and monogamous great tits: does the polygyny-threshold model hold? 213

Dingle, Hugh. See Francis R. Groeters Dixon, A. F. G., P. Kindlmann, J. Lepš, 
and J. Holman. Why there are so few species of aphids, especially in the tropics, 580

Dobson, F. Stephen, and Jan O. Murie. Interpretation of intraspecific life history patterns: evidence from Columbian ground squirrels, 382; Erratum, 941

Dunford, Christopher. See Russell Davis

Eadie, John McA., Louis Broekhoven, and Patrick Colgan. Size ratios and artifacts: Hutchinson's rule revisited, 1

Earle, Michael. A flexible body mass in social carnivores, 755

Ferrari, James A. See Charles E. Taylor Ferson, Scott. See Daniel Wartenberg Frost, Thomas M. See Timothy K. Kratz

Gabriel, Wilfried. See Michael Lynch

Gaso, M. I. See L. Levine

Godfray, H. C. J. The evolution of clutch size in parasitic wasps, 221. See also Paul H. Harvey

Goldman, D. A. See Mary F. Willson

González, F. See L. Levine

Groeters, Francis R., and Hugh Dingle. Genetic and maternal influences on life history plasticity in response to photoperiod by milkweed bugs (Oncopeltus fasciatus), 332

Gross, Mart R. See Robert Craig SARGENT

Gurney, W. S. C. See W. W. Murdoch

Guzmán, J. See L. Levine

Hanlon, Roger T., and B.-U. BudelMANN. Why cephalopods are probably not "deaf," 312

Harvey, Paul H., and H. C. J. Godfray. How species divide resources, 318

HestBeCK, JAY B. Multiple regulation states in populations of small mammals: a state-transition model, 520

Holman, J. See A. F. G. Dixon

Hoppes, W. G. See Mary F. Willson

Hughes, Terence P., and Joseph H. ConNELL. Population dynamics based on size or age? A reef-coral analysis, 818

Huston, M. A., and D. L. DeAngelis. Size bimodality in monospecific populations: a critical review of potential mechanisms, 678
Jenkins, Stephen H. See Jeffrey B. LLEWELLYN

Jordano, Pedro. Patterns of mutualistic interactions in pollination and seed dispersal: connectance, dependence asymmetries, and coevolution, 657

Jumars, Peter A. See Deborah L. Penry

Katusic-Malmborg, P. L. See Mary F. WILLSON

Kerszberg, Michel. See Zvia Agur

Kindlmann, P. See A. F. G. Dixon

Kitchell, James F. See Stephen R. CarPENTER

Kratz, Timothy K., Thomas M. Frost, and JoHn J. MaGnuson. Inferences from spatial and temporal variability in ecosystems: long-term zooplankton data from lakes, 830

Krishnan, V. V. See J. A. Stamps

LEPŠ, J. See A. F. G. Dixon

Lessells, C. M., and M. I. Avery. Sexratio selection in species with helpers at the nest: some extensions of the repayment model, 610

LEVEY, Douglas J. Seed size and fruit-handling techniques of avian frugivores, 471

Levine, L., O. Olvera, R. F. Rockwell, M. E. DE la Rosa, E. Akin, M. I. Gaso, F. González, and J. Guzmán. Chromosomal and behavioral studies of Mexican Drosophila. V. Frequencies of multiple insemination in three natural populations, 458

Llewellyn, Jeffrey B., and Stephen H. JENKINS. Patterns of niche shift in mice: seasonal changes in microhabitat breadth and overlap, 365

LLOYD, DAvid G. Selection of offspring size at independence and other sizeversus-number strategies, 800

LyNCH, Michael, and Wilfried Gabriel. Environmental tolerance, 283

MacDonald, Glen M. See Les C. Cwynar Magnuson, John J. See Timothy K. KRATZ

Marks, JefFrey S., and Roland L. RedMOND. Parent-offspring conflict and natal dispersal in birds and mammals: comments on the Oedipus hypothesis, 158 
Maynard Smith, J. See G. A. Parker

McCauley, Edward, and William W. MurdoCH. Cyclic and stable populations: plankton as paradigm, 97

Meffe, Gary K., and Martha L. Crump. Possible growth and reproductive benefits of cannibalism in the mosquitofish, 203

Miles, Donald B., Robert E. Ricklefs, and Joseph Travis. Concordance of ecomorphological relationships in three assemblages of passerine birds, 347

MOORE, R. See J. J. Bull

Murdoch, W. W., R. M. Nisbet, S. P. Blythe, W. S. C. Gurney, and J. D. ReEve. An invulnerable age class and stability in delay-differential parasitoid-host models, 263

Murdoch, William W. See Edward MCCAULEY

Murie, Jan O. See F. Stephen Dobson

Murray, K. Greg. Selection for optimal fruit-crop size in bird-dispersed plants, 18

Ng, D. See J. J. Bull

Nisret, R. M. See W. W. Murdoch

Nudds, Thomas D. See M. Julian Caley

Oden, Neal L. See Robert R. Sokal

Olvera, O. See L. Levine

Paige, Ken N., and Thomas G. Whitham. Overcompensation in response to mammalian herbivory: the advantage of being eaten, 407

PARker, G. A., and J. Maynard Smith. The distribution of stay times in Scatophaga: a reply to Curtsinger, 621

Penry, Deborah L., and Peter A. Jumars. Modeling animal guts as chemical reactors, 69

Pereda, Amalia D. See Charles E. TAYLOR

Raffa, Kenneth F., and Alan A. BerryMAN. Interacting selective pressures in conifer-bark beetle systems: a basis for reciprocal adaptations? 234

Redmond, Roland L. See JefFrey S. MARKS

ReEkIE, E. G., and F. A. BAzZaZ. Reproductive effort in plants. 1. Carbon allocation to reproduction, 876
Reproductive effort in plants. 2 .

Does carbon reflect the allocation of other resources? 897

- Reproductive effort in plants. 3 .

Effect of reproduction on vegetative activity, 907

Reeve, J. D. See W. W. Murdoch

Ricklefs, Robert E. See Donald B. Miles

Rockwell, R. F. See L. Levine

Rohlf, F. James. See Daniel Wartenberg

Rotenberry, John T. See John A. Wiens

Roughgarden, Jonathan. See Sally BLOWER

Sargent, Robert Craig, Peter D. Taylor, and MART R. Gross. Parental care and the evolution of egg size in fishes, 32

Sokal, Robert R., Neal L. Oden, and J. S. F. BARKER. Spatial structure in Drosophila buzzatii populations: simple and directional spatial autocorrelation, 122

Stamps, J. A. Conspecifics as cues to territory quality: a preference of juvenile lizards (Anolis aeneus) for previously used territories, 629

Stamps, J. A., M. Buechner, and V. V. KrishnaN. The effects of edge permeability and habitat geometry on emigration from patches of habitat, 533

Stephenson, A. G. See J. A. Winsor

Swain, D. P. A problem with the use of meristic characters to estimate developmental stability, 761

Taylor, Charles E., Amalia D. Pereda, and James A. Ferrari. On the correlation between mating success and offspring quality in Drosophila melanogaster, 721

Taylor, Peter D. See Robert Craig SARGENT

Thomas, P. A. See Mary F. Willson

Thompson, C. See J. J. Bull

Tilman, David. The importance of the mechanisms of interspecific competition, 769

Travis, Joseph. See Donald B. Miles

Tsuji, Nobuyuki. See Norio Yamamura

Turelli, Michael. See Jerry A. Coyne

Wallace, Bruce. Ritualistic combat and allometry, 775

Wallin, KJell. See David W. WinkLer 
WARD, S. A. Optimal habitat selection in time-limited dispersers, 568

Wartenderg, Daniel, Scott Ferson, and F. James Rohlf. Putting things in order: a critique of detrended correspondence analysis, 434

Waser, Nickolas M. See Diane R. CampBELL

Whitham, Thomas G. See Ken N. Paige

WiEns, John A., and JoHn T. ROTENBERRY. Shrub-steppe birds and the generality of community models: a response to Dunning, 920

Willson, Mary F., W. G. Hoppes, D. A. Goldman, P. A. Thomas, P. L.

Katusic-MalmboRg, and J. L. BothWELL. Sibling competition in plants: an experimental study, 304

WinkLer, David W., and KJell Wallin.
Offspring size and number: a life history model linking effort per offspring and total effort, 708

Winsor, J. A., L. E. Davis, and A. G. STEPHENSON. The relationship between pollen load and fruit maturation and the effect of pollen load on offspring vigor in Cucurbita pepo, 643

WoOD, JAMES $\mathrm{W}$. The genetic demography of the Gainj of Papua New Guinea. 2. Determinants of effective population size, 165

Wool, DAvid. Differentiation of island populations: a laboratory model, 188

Yamamura, Norio, and Nobuyuki Tsuji. Optimal patch time under exploitative competition, 553

\section{Alphabetical Table of Contents of Titles}

Anisogamy overcome: female strategies in snail kites. Steven R. Beissinger, 486

Chromosomal and behavioral studies of Mexican Drosophila. V. Frequencies of multiple insemination in three natural populations. L. Levine, O. Olvera, R. F. Rockwell, M. E. de la Rosa, E. Akin, M. I. Gaso, F. González, and J. Guzmán, 458

Concordance of ecomorphological relationships in three assemblages of passerine birds. Donald B. Miles, Robert E. Ricklefs, and Joseph Travis, 347

Conspecifics as cues to territory quality: a preference of juvenile lizards (Anolis aeneus) for previously used territories. J. A. Stamps, 629

Cyclic and stable populations: plankton as paradigm. Edward McCauley and William W. Murdoch, 97

Differentiation of island populations: a laboratory model. David Wool, 188

The distribution of stay times in Scatophaga: a reply to Curtsinger. G. A. Parker and J. Maynard Smith, 621

Do female yellow-bellied marmots adjust the sex ratios of their offspring? Kenneth B. Armitage, 501
The effects of edge permeability and habitat geometry on emigration from patches of habitat. J. A. Stamps, M. Buechner, and V. V. Krishnan, 533

The effects of grazing: confounding of ecosystem, community, and organism scales. A. J. Belsky, 777

The emergence of phenotypic novelties through progressive genetic change. Zvia Agur and Michel Kerszberg, 862

Environmental tolerance. Michael Lynch and Wilfried Gabriel, 283

The Evolutionary Dys-Synthesis: which bottles for which wine? Janis Antonovics, 321

The evolution of clutch size in parasitic wasps. H. C. J. Godfray, 221

Evolution of concealed ovulation in vervet monkeys (Cercopithecus aethiops). Sandy J. Andelman, 785

The evolution of plant mating systems: multilocus simulations of pollen dispersal. Diane R. Campbell and Nickolas M. Waser, 593

An example of contemporary colonization of montane islands by small, nonflying mammals in the American Southwest. Russell Davis and Christopher Dunford, 398 
A flexible body mass in social carnivores. Michael Earle, 755

Genetic and maternal influences on life history plasticity in response to photoperiod by milkweed bugs (Oncopeltus fasciatus). Francis R. Groeters and Hugh Dingle, 332

The genetic demography of the Gainj of Papua New Guinea. 2. Determinants of effective population size. James W. Wood, 165

Geographical variation of lodgepole pine in relation to population history. Les $C$. Cwynar and Glen M. MacDonald, 463

How species divide resources. Paul $\mathrm{H}$. Harvey and H. C. J. Godfray, 318

The importance of the mechanisms of interspecific competition. David Tilman, 769

Inferences from spatial and temporal variability in ecosystems: long-term zooplankton data from lakes. Timothy $\mathrm{K}$. Kratz, Thomas M. Frost, and John J. Magnuson, 830

Interacting selective pressures in coniferbark beetle systems: a basis for reciprocal adaptations? Kenneth F. Raffa and Alan A. Berryman, 234

Interpretation of intraspecific life history patterns: evidence from Columbian ground squirrels. F. Stephen Dobson and Jan O. Murie, 382; Erratum, 941

An invulnerable age class and stability in delay-differential parasitoid-host models. W. W. Murdoch, R. M. Nisbet, S. P. Blythe, W. S. C. Gurney, and J. D. Reeve, 263

Long-distance migration of Drosophila. 2. Presence in desolate sites and dispersal near a desert oasis. Jerry A. Coyne, Stephen H. Bryant, and Michael Turelli, 847

A model for natural selection of genetic migration. J. J. Bull, C. Thompson, D. $\mathrm{Ng}$, and $\mathrm{R}$. Moore, 143

Modeling animal guts as chemical reactors. Deborah L. Penry and Peter A. Jumars, 69

Multiple regulation states in populations of small mammals: a state-transition model. Jay B. Hestbeck, 520
Offspring size and number: a life history model linking effort per offspring and total effort. David W. Winkler and Kjell Wallin, 708

On the correlation between mating success and offspring quality in Drosophila melanogaster. Charles E. Taylor, Amalia D. Pereda, and James A. Ferrari, 721

Optimal habitat selection in time-limited dispersers. S. A. Ward, 568

Optimal patch time under exploitative competition. Norio Yamamura and Nobuyuki Tsuji, 553

Overcompensation in response to mammalian herbivory: the advantage of being eaten. Ken N. Paige and Thomas G. Whitham, 407

Parental care and the evolution of egg size in fishes. Robert Craig Sargent, Peter D. Taylor, and Mart R. Gross, 32

Parent-offspring conflict and natal dispersal in birds and mammals: comments on the Oedipus hypothesis. Jeffrey S. Marks and Roland L. Redmond, 158

Patterns of mutualistic interactions in pollination and seed dispersal: connectance, dependence asymmetries, and coevolution. Pedro Jordano, 657

Patterns of niche shift in mice: seasonal changes in microhabitat breadth and overlap. Jeffrey B. Llewellyn and Stephen H. Jenkins, 365

Polinices predation patterns and Mercenaria morphology models. John A. Commito, 449

Polygynous blue tits and monogamous great tits: does the polygyny-threshold model hold? André A. Dhondt, 213

Population dynamics and parasitic castration: a mathematical model. Sally Blower and Jonathan Roughyarden, 730

Population dynamics based on size or age? A reef-coral analysis. Terence $P$. Hughes and Joseph H. Connell, 818

Possible growth and reproductive benefits of cannibalism in the mosquitofish. Gary K. Meffe and Martha L. Crump, 203

A problem with the use of meristic characters to estimate developmental stability. D. P. Swain, 761

Putting things in order: a critique of de- 
trended correspondence analysis.

Daniel Wartenberg, Scott Ferson, and

F. James Rohlf, 434

The relationship between pollen load and fruit maturation and the effect of pollen load on offspring vigor in Cucurbita pepo. J. A. Winsor, L. E. Davis, and A. G. Stephenson, 643

Reproductive effort in plants. 1. Carbon allocation to reproduction. E. G. Reekie and F. A. Bazzaz, 876

Reproductive effort in plants. 2. Does carbon reflect the allocation of other resources? E. G. Reekie and F. A. Bazzaz, 897

Reproductive effort in plants. 3. Effect of reproduction on vegetative activity. E. G. Reekie and F. A. Bazzaz, 907

Ritualistic combat and allometry. Bruce Wallace, 775

Seed size and fruit-handling techniques of avian frugivores. Douglas J. Levey, 471

Selection for optimal fruit-crop size in birddispersed plants. K. Greg Murray, 18

Selection of offspring size at independence and other size-versus-number strategies. David G. Lloyd, 800

Senescence and the genetic-correlation hang-up. Andrew G. Clark, 932

Sex-ratio adjustment in Odocoileus: does local resource competition play a role? M. Julian Caley and Thomas D. Nudds, 452

Sex-ratio selection in species with helpers at the nest: some extensions of the repayment model. C. M. Lessells and M. I. Avery, 610

Shrub-steppe birds and the generality of community models: a response to

Dunning. John A. Wiens and John T.

Rotenberry, 920

Sibling competition in plants: an experimental study. Mary F. Willson, W. G. Hoppes, D. A. Goldman, P. A. Thomas, P. L. Katusic-Malmborg, and J. L. Bothwell, 304

The significance of spider size to the diversification of spider-web architectures and spider reproductive modes. Catherine L. Craig, 47

Size bimodality in monospecific populations: a critical review of potential mechanisms. M. A. Huston and D. L. DeAngelis, 678

Size ratios and artifacts: Hutchinson's rule revisited. John McA. Eadie, Louis Broekhoven, and Patrick Colgan, 1

Smaller zooplankton species are not superior in exploitative competition: a comment on Persson. Jan Bengtsson, 928

Spatial structure in Drosophila buzzatii populations: simple and directional spatial autocorrelation. Robert R. Sokal, Neal L. Oden, and J. S. F. Barker, 122

The temporal scale of variance in limnetic primary production. Stephen R. Carpenter and James F. Kitchell, 417

Why cephalopods are probably not "deaf." Roger T. Hanlon and B.-U. Budelmann, 312

Why there are so few species of aphids, especially in the tropics. A. F. G. Dixon, P. Kindlmann, J. Lepš, and J. Holman, 580 